\title{
La informalidad como desregulación del Estado. Las zonas de penumbra de la ciudad post-colonial
}

Sección ESTUDI0S

RECIBIDO: $15 / 07 / 2020$

APROBADO: 30/08/2020

PUBLICADO ONLINE: 30/11/2021
Luis Rodríguez Rivero

Grupo de Investigación CONURB - Facultad de Arquitectura y Urbanismo - PUCP

lerodrig@pucp.edu.pe

https://orcid.org/0000-0002-2980-485X

\section{RESUMEN}

Lo que entendemos como informalidad existía mucho antes de ser acuñado el término, para un mejor entendimiento del fenómeno resulta necesario rastrear los orígenes de aquellas actividades que a través del tiempo se han realizado al margen del ordenamiento legal que define formalmente al estado-nación moderno. El artículo busca articular el fenómeno informal contemporáneo a otros modos de existir al margen de la legalidad que tienen su origen en los regímenes coloniales, caracterizados por la necesidad de implementar sistemas de gobierno y legales paralelos. Se trata de entender la informalidad como un fenómeno propio de las situaciones postcoloniales y proponer salidas desde esa lectura.

PALABRAS CLAVE: Informalidad, postcolonialidad, discurso del amo, desregulación.

Informality as de-regulation of the state. The twilight zones of the post-colonial city

\section{ABSTRACT}

What we understand as informality existed a long time before the term was coined. For a better understanding of the phenomenon, it is necessary to trace the origins of those activities that over time have been carried outside the legal system that formally defines the modern nation-state. The article seeks to articulate the contemporary informal phenomenon to other ways of existing outside the law that have their origin in colonial regimes, characterized by the need to implement parallel government and legal systems. It is about understanding informality as a phenomenon typical of postcolonial situations and proposing ways out from that reading.

KEYWORDS: Informality, postcoloniality, master's speech, deregulation.

(c) Los autores. Este artículo es publicado por la Revista de Sociología de la Facultad de Ciencias Sociales, Universidad Nacional Mayor de San Marcos. Este es un artículo de acceso abierto, distribuido bajo los términos de la licencia Creative Commons Atribución 4.0 Internacional (CC BY 4.0) [https://creativecommons.org/licenses/by/4.0/deed.es] que permite el uso, distribución y reproducción en cualquier medio, siempre que la obra original sea debidamente citada de su fuente original. 


\section{Introducción}

El presente texto es una reflexión de orden histórico y teórico sobre la naturaleza de la informalidad urbana en el marco de la discusión sobre la descolonización del saber urbano ', que busca resituar el debate en una revisión del concepto de Estadonación y el modelo de ciudad vinculado a él como unidad orgánica y simbólica. Esa unidad supone que la ciudad, toda ella, debe ser controlada y soportada desde el Estado mediante sus reglas y recursos, como única vía posible para su existencia. Desde ese punto de vista, todo aquello que no responde a las normas y controles del estado debe considerarse fuera de la norma, ilegal, es decir, informal. El artículo es un primer paso en el objetivo de pensar en un tipo de estado más real, que acepte su incapacidad para responder a las demandas de la totalidad del territorio y de la población, que asuma la informalidad como una característica de origen, que pueda discernir entre la informalidad y la ilegalidad, entre lo que ella tiene de supervivencia y lo que tiene de corrupción, y que desde esa lectura apueste por una redefinición de lo que debe ser el Estado-nación. Si bien el artículo busca abrir la discusión a distintas realidades, usa Lima como centro de observación dada la importancia que el proceso histórico de la ciudad y el desarrollo teórico han tenido en el entendimiento de lo informal a nivel mundial.

El debate sobre el concepto específico de informalidad y sus efectos en las ciudades de los países en desarrollo cumplirá el 2022 medio siglo, desde que se acuñara el término sector informa ${ }^{2}$ en referencia al empleo de una gran parte de la población de ciudades como Accra en Ghana o Nairobi en Kenia, cuyo trabajo se desarrollaba al margen de las normas, autorizaciones y registros de las autoridades del Estado. Los primeros estudios señalaban que esa falta de control ocasionaba un

1 Este artículo está basado en el Capítulo 8: Economía libidinal y Estado del espejo, de la tesis doctoral Los Imaginarios Urbanos y el futuro de la ciudad. Postcolonialidad y Reapropiaciones (2020) del autor, desarrollada en la ENSAV, Versalles, Francia, bajo la dirección de los doctores Wiley Ludeña y Philippe Potié.

2 El término informalidad se utiliza por primera vez para referirse a temas de empleo y economía. Sobre su origen existe cierta discrepancia. Para Mike Davis (2007) ha sido Keith Hart (1973) en su artículo Informal Income Opportunities and Urban Employement in Ghana (Cambridge University Press) la primera vez que se menciona "sector informal". Efectivamente, no sólo se acuña el término, sino que en la 8va página del artículo Hart ensaya una definición para el sector informal de ingresos urbanos como aquel donde los trabajadores se proveen ellos mismos de un empleo que, sin embargo, posee una racionalidad menor en términos de regularidad. Esta definición se opone implícitamente a la del sector formal que es entendido como un sector laboral moderno (1973, p. 8). De otro lado, Kalyan Sanyal (2007) apunta que el término fue acuñado en 1972 por la OIT en el reporte hecho marco del World Employment Program (WEP) Employment, incomes and equality. An estrategy for increasing productive employment in Kenya. Donde en efecto, en el sub-capítulo 22. The relation between the formal and informal sectors, donde este se define como el sector frecuentmeente ignorado por las autoridades, fuera del sistema de beneficios del Estado, que opera fuera de la legalidad, entre varios aspectos, lo que genera una situación laboral riesgosa e incierta, con bajos ingresos (1972, p. 504). 
empleo precario, inestable, sin ningún tipo de seguridad y con ingresos muy bajos, casi de subsistencia. Tanto en el artículo de Keith Hart (1973) como en el reporte de la WEP de la OIT (1972), se establece una relación directa entre el sector formal y lo moderno, siendo implícitamente el sector informal definido por rasgos no modernos. La modernidad se materializaba en un marco normativo que a través de las instituciones del estado definían las condiciones en que el empleo debe darse, en otras palabras, lo moderno es lo articulado desde el Estado, mientras lo informal es aquello que se disocia, se aleja de las regulaciones del estado para definir las suyas propias.

Para ambos ensayos fundadores del concepto de lo informal, este sector tiene dos características adicionales, de un lado, está formado básicamente por personas que han migrado del mundo rural hacia las ciudades debido a la falta de oportunidades para salir del atraso en que se encontraban. De otro lado, desde los estudios iniciales se ha señalado su enorme capacidad creativa, la que le permitía inventar oficios, productos y procesos inexistente para así satisfacer las demandas que el Estado no era capaz de atender (De Soto, 1987, p. 12). En las últimas décadas del siglo XX la informalidad como preocupación, se ha desplazado desde el campo de la economía y el empleo hacia lo urbano, permitiendo hablar primero de la vivienda informal, luego de comercio informal, para acabar usando el término ciudad informal para referirse a las partes de la ciudad desarrolladas al margen de las normas del estado. Se puede afirmar que la mirada contemporánea sobre el fenómeno general de la informalidad no ha cambiado sustancialmente desde la aproximación inicial, lo informal aún es visto como la consecuencia de falta de acciones al interior del territorio nacional donde el estado no ha logrado ni satisfacer expectativas ni imponer sus reglas o, donde luego de haberlas impuesto no ha podido mantener las condiciones para su cumplimiento. Fraseado de otra manera diríamos que se trata de un proceso de desregulación al interior del propio estado, que intenta imponer un sistema normativo y legal y fracasa en ese intento.

La literatura suele ver el problema en una sola dirección, desde el Estado que emite una norma hacia el ciudadano que está obligado a cumplirla, así, la desregulación tiene un carácter simple, el no cumplimiento de la regla, y una dirección, de arriba hacia abajo. Si aceptamos la complejidad de lo urbano debemos rechazar la sobre simplificación de esta mirada, y aceptar que es necesario matizarla. Para empezar, las situaciones que generan la informalidad tienen en común la desidia constante del estado para brindar iguales oportunidades a todos sus ciudadanos. En segundo lugar, las normar que se dictan no siempre son las adecuadas, el estado siempre tiene dificultades para leer la realidad y tiene problemas para aceptar 
otras lecturas, como las provenientes de la academia y de actores más cercanos a la sociedad. La desregulación va más allá de la falta de cumplimiento de la ley.

Tal vez la pregunta —y la mirada — debe colocarse en la propia desregulación y no en alguno de los actores, tratando de entender su naturaleza, origen y procesos, en un marco amplio que permita abarcar el espectro de lo subjetivo. La desregulación ${ }^{3}$ se entiende en este artículo como el proceso a través del cual un sujeto disuelve su presencia del lugar simbólico que ocupa o debe ocupar. En rigor, se trata de la desregulación del lugar del discurso del amo en la ecuación lacaniana ${ }^{4}$, que se define como una estructura que define el discurso más allá de las palabras, desde la naturaleza del propio lugar de enunciación. Al hacerse menos legible su presencia, el mandato simbólico que de él emana se dificulta igualmente su legibilidad, debilitando todo el sistema y desregulándolo. La desregulación implica la ruptura de jerarquías y de normas que permiten que el sistema funcione adecuadamente, y como en cualquier sistema, una falla en una de las partes tiene consecuencias en las demás, más aún si la falla se encuentra en los elementos prioritarios. Finalmente, la desregulación pasa por la emisión de discursos (acciones) contradictorios entre sí, que en última instancia se anulan entre y contribuyen más a la desregulación misma.

En la situación colonial el lugar del discurso del amo es tomado por el colonizador, sin embargo, como se tratará de mostrar en este artículo, los actos del propio colonizador socavan la presencia de su discurso, provocando una segunda desregulación — la primera es el propio acto de conquistar una tierra ajena - que va deslegitimando su presencia, como se verá más adelante. Esto obligó a la existencia de formas de gobierno o gestión paralelas, típicas de los regímenes coloniales. La ausencia de una ruptura clara con ese paralelismo en el paso del régimen colonial al republicano con la independencia, permite la continuidad de sistema paralelos de gobierno/gestión, que a la larga darán lugar a lo que se entiende como informalidad (Rodríguez, 2020). El lugar del discurso del amo será tomado por las élites locales que, entre otros aspectos, buscan introducir las nociones de modernidad occidental como parte de sus esfuerzos por perpetuar sus privilegios, creando un régimen de excepción respecto al propio régimen democrático. De esta manera, los

3 La introducción del concepto de desregulación del sujeto en el discurso del amo vinculado a los procesos de informalidad fue presentada por el Sociólogo y psicoanalista Luis López Espinoza, en el marco del Seminario de investigación: Informalidades urbanas en la ciudad autoconstruida: ¿Hacia una agenda de investigación?", organizado por el grupo de trabajo Informalidades Urbanas, llevado a cabo el 29 de agosto del 2018 en la PUCP, Lima.

4 Jacques Lacan toma de Hegel el esquema de relación entre el amo y el esclavo, que generan una dependencia mutua en tanto uno toma el lugar del otro alternativamente. Para Lacan, en la ecuación S1/\$ // S2/a S1 es el lugar de enunciación del discurso del amo, se trata de un lugar vaciado de significación, que será ocupado indistintamente por otros discursos en el permanente juego de desplazamientos de significantes. 
esfuerzos de modernización de los recién fundados Estado-nación post-coloniales, no hacen sino reproducir la escisión originada por el proceso de colonización, transformando la división colonizadores-colonizados (europeos-indígenas), en élites ${ }^{5}$ -indígenas desde la independencia hasta la segunda mitad del siglo XX, y más tarde en formales e informales, como otra forma de instauración de regímenes paralelos.

En los países en desarrollo la magnitud de esa desregulación debería plantear preguntas urgentes, el promedio de informalidad urbana en el hemisferio sur es mayor al 50\% (India 90\%, Perú 70\%, México 50\%). Esto parecería decir que existen estados que sólo gestionan o gobiernan entre el $30 \%$ y $10 \%$ de lo que ocurre en su territorio. ¿No debería leerse acaso ese $90 \%$ o $70 \%$ como un estado en sí mismo, un estado alterno, desregulado y en muchos casos mayor que el Estado-nación oficial? Sin embargo, si asumimos que el fenómeno informal tiene su origen en la propia constitución del estado nación de los países post-coloniales ${ }^{6}$, ese estado paralelo constituye una construcción del propio Estado-nación, es el resto no resuelto de lo colonial que se traslada a la república moderna. Se trataría de un "estado de excepción"7 en el sentido en que lo enuncia Agamben, como el régimen paralelo instaurado por el propio soberano y que se origina en una necesidad que no puede pasar por una forma jurídica, y que se encuentra “... entre lo político y lo jurídico y entre el derecho y lo viviente..." $(2019$, p. 28). Se trata por lo tanto de un umbral, de una "franja ambigua e incierta en la intersección entre lo jurídico y lo político" (Agamben, 2019, p. 27), de un espacio de indefinición que no está en el lado opuesto de lo legal, sino que en ciertos aspectos y momentos formaría parte del propio Estado.

\section{La informalidad, ¿un concepto en penumbra?}

El crecimiento desmesurado y la informalidad urbana han sido características de las ciudades de los países en desarrollo durante el siglo XX y XXI, sin embargo, paradójicamente, la literatura que mayor difusión e impacto tiene en el mundo académico y profesional en el hemisferio sur es frecuentemente la que se origina

5 Dependiendo de la realidad de cada país serán mestizos, criollos o una élite con las mismas características étnicas pero una posición mayor debido a algún régimen (castas) o a su acción en la lucha independentista.

6 Aquí debería introducirse la discusión de si el Estado-nación tal como se construyó debería ser el modelo asumido por las naciones post-coloniales, si seguimos a Partha Chatterjee en La nación en tiempo heterogéneo (2007), la respuesta está más cerca del no que del sí.

7 No se trata de la "excepción" en su sentido lato de una singularidad o la excepción a la regla, sino del que le da Giorgio Agambem en su trilogía Homo Sacer. 
en el mundo desarrollado ${ }^{8}$. La imagen de lo urbano en el mundo se complementa con las ideas sobre las ciudades globales, conceptualizadas como los nodos de información del sistema global que "modela" el resto de ciudades del planeta (Roy, 2005, p. 1). En esa lógica la informalidad aparece como el resto que se opone a la planificación urbana, surgida en Inglaterra como la disciplina que permite al Estado el control del crecimiento y desarrollo de las ciudades y el territorio a partir de la industrialización. Como lo señala Roy (2005), la informalidad se plantea como aquello que impide al Estado planificar, sin embargo, esta dicotomía sólo es válida desde la manera como se define la propia informalidad. Por ejemplo, en el caso de De Soto (1987), se esfuerza por mostrar la informalidad como el problema de una parte de la población para atravesar una serie de barreras burocráticas que el Estado construye desde su sistema legal, lo que les impide acceder al mercado y al sistema capitalista pleno, dificultando su salida de la pobreza y precariedad (De Soto, 1997, p. 171). Diversos autores coinciden en que esta es una lectura sesgada del fenómeno informal (Roy, 2005, p. 2) (Calderón, 2019, p. 46) (Sanyal, 2007, p. 200), guiada seguramente por la postura neoliberal del autor de El otro sendero que se esmera en argumentar la necesidad de desmantelar el Estado. Pero su propia descripción "empírica" del fenómeno evidencia que la oposición entre informalidad y legalidad no están marcada como el autor pretende afirmarlo:

La informalidad no es tampoco un sector preciso ni estático de la sociedad, sino una zona de penumbra que tiene una larga frontera con el mundo legal y donde los individuos se refugian cuando los costos de cumplir las leyes exceden a sus beneficios. Sólo en contados casos la informalidad implica no cumplir con todas las leyes; en la mayoría, se desobedecen disposiciones legales precisas de una manera que describiremos más adelante. También son informales aquellas actividades para las cuales el Estado ha creado un sistema legal de excepción a través del cual un informal puede seguir desarrollando sus actividades, aunque sin acceder necesariamente a un status legal equivalente al de aquellos que gozan de la protección y los beneficios de todo el sistema legal peruano. (De Soto, 1987, p. 12)

Se observa que Estado e informalidad no se encuentran en las antípodas, por el contrario, ambos cohabitan esa "zona de penumbra", pero tal vez la afirmación clave es la aceptación que los sistemas al margen de la legalidad se dan por acción del

8 Por ejemplo, es en EE. UU. donde nace la categoría de megaciudad, definidas por su población, mayor a 10 millones de habitantes como consecuencia de la globalización (UN, 2018, p. 55). Lo mismo con la noción de Post-Metrópolis de Edward Soja (2000) o la de Metápolis de François Ascher (1995). Sin embargo, una mirada a las ciudades que entran en esa definición nos muestra que ninguna ciudad entre las 10 primeras de esa lista pertenece a Europa. Esto es materia de desarrollo en las últimas décadas bajo la noción de violencia epistémica, introducida a lo urbano a través del texto de Spivak Gayatri ¿Puede hablar el sujeto subalterno? 
propio Estado al generar estados de excepción. Esto abona a la idea de un Estado que al generar excepciones promueve la informalidad, la que talvez no se produciría por las dificultades para acceder a la legalidad por las trabas sino a un sistema contradictorio de normas que buscan generar excepciones aprovechadas luego por sectores de la economía. Si bien, como afirma Calderón, "La línea que divide lo formal de lo informal, es el quiebre de la ley" (Calderón, 2019, p. 46), debe decirse que esa línea es lo suficientemente ancha como para que el mismo Estado pueda encontrarse por momentos dentro de ella.

\section{La informalidad urbana y las barriadas}

Las barriadas contemporáneas ${ }^{9}$ de América Latina, Asia y África, tienen sus orígenes entre finales del siglo XIX e inicios del XX, 50 años antes de la aparición del término informalidad. Fue en ese mismo momento cuando las ideas urbanas modernas provenientes de Europa fueron introducidas por las élites locales en América Latina y por los colonizadores europeos en Asia o África. Las nuevas ideas tenían como objetivo "ordenar" el espacio urbano y el territorio, siguiendo las lógicas del recién inventado zooning o zonning, basado en criterios sanitarios que sin embargo escondían prejuicios raciales y morales, dando como resultado una ciudad segregada ${ }^{10}$. Estos barrios precarios fueron creciendo simultáneamente a las transformaciones que sufren las zonas centrales de las grandes capitales, que incorporan las mejoras aparecidas en las ciudades europeas hacia el final del siglo XIX, iluminación púbica, asfalto, parques, equipamiento público, etc. La magnitud de estas primeras barriadas puede compararse a las que existían a finales del siglo XIX en las capitales europeas, como en los bordes de Paris donde cerca de 9000 "cartoneros" vivían en refugios en zonas como Port Dorée, con dinámicas parecidas a las que luego se darían en el hemisferio sur. "Según un escritor contemporáneo, buscaron vastas tierras abiertas en las afueras de París y tan pronto como uno descubría una casa o un sitio disponible para alquilar, todos los demás vinieron a visitar y rápidamente formaron un asentamiento, un clan, una familia"11

9 Decimos contemporáneas porque la formación de barrios precarios en América se dio desde el momento que se inicia la construcción de las ciudades coloniales, especialmente en las capitales del siglo XVI, México y Lima, formándose asentamientos marginales y obviamente informales en los alrededores, los que se mantuvieron hasta entrada el período republicano.

10 El zoning, aplicado por Burguess en Chicago en 1923 es la primera aplicación de las ideas enunciadas por Baumeister en 1870, que da como resultado una ciudad segregada en términos étnicos y socio-económicos. De otro lado, en L'Urbanisme Aux Colonies et dans les Pays Tropicaux (1932) se señalan con total claridad los criterios urbanos a ser aplicados en las ciudades coloniales.

11 Traducción por el autor. 
(Bayode, 2019, p. 191). A diferencia de lo ocurrido en el hemisferio sur estos asentamientos nunca pasaron de las 5 mil personas, y fue durante la remodelación encabezada por el barón de Haussmann que el Estado francés inicia un proceso de incorporación de estos sectores de la población a la ciudad, construyendo vivienda social en el borde de Paris, y finalmente al propio Estado.

La experiencia europea, eliminar las barriadas a partir intervenciones monumentales y de la aplicación de la zonificación, devino a inicios del siglo XX en la política urbana por excelencia en la África y Asia coloniales, pero también en la América Latina recién independizada. Ese traslado de conocimientos y enfoques no ha cesado a pesar de que la mayor parte de países obtuvieran su independencia, la autonomía en la mirada y acciones sobre las ciudades sigue siendo una aspiración, "las políticas internacionales actuales que abordan la ciudad africana están situadas en una historia más larga que se remonta al período colonial, imbuida de una afirmación de la supremacía civilizadora europea en términos de un enfoque de desarrollo moderno (TA)." (Bayode, 2019, p. 198). Para la década de 1940 a las estrategias mencionadas se suma la construcción de vivienda social ${ }^{12}$ pero, paradójicamente, las barriadas no disminuyen, sino que van aumentando en cantidad y en magnitud. El urbanismo y la vivienda social moderna se mantienen incólumes, la necesidad de erradicar las barriadas deja de ser pensada desde el urbanismo para ser asumida desde otros lugares, las políticas urbanas sin mayor relación con lo que se construía, una premisa que subsiste hasta hoy en diversos países $^{13}$. Esto permite rastrear el origen de la ideología urbana moderna en el hemisferio sur y su escisión de la realidad, haciéndose además transparente lo que desde le urbanismo era deseable como ciudad en los países en desarrollo.

También permite poner en evidencia que la desaparición de los slums europeos coincide con la aparición del Estado-nación imperial, cuyos abundantes recursos provenientes de las propias colonias, permitió que transformaran sus capitales, convirtiéndolas en símbolos de poder y cultura. Fue por lo tanto la acción de ese Estado fuerte la que absorbió la población marginal, dándole no solo un lugar para vivir, sino además integrándola al mercado laboral y asignándole el estatus de ciudadano. Ese estado fuerte e imperial no actúa con la misma decisión y disposición de recursos en las colonias, donde la precariedad económica, laboral y urbana es mucho mayor, pero donde también sus políticas urbanas tienen otro sesgo, el de

12 En Venezuela el conjunto 12 de enero, en Perú las Unidades Vecinales № 3 y Matute, en Brasil Pedregulho, entre otros.

13 Esta ha sido una constante casi generalizada desde la Europa del siglo XIX, sin embargo, salvo excepciones como los programas de vivienda llevados a cabo por Écochard en Casablanca por el protectorado francés, nunca estas iniciativas llegaron a tener éxito. 
entender a los colonizados como "indígenas" (indigènes), sin el mismo estatus ni derechos que los colonizadores (Royer, 1932).

\section{La informalidad en Lima}

El proceso de formación de las barriadas en el caso de Lima, la capital peruana, no ha sido la excepción, mientras desde el Estado se buscaba construir esa ciudad deseada, moderna y bien equipada, las barriadas crecían en la periferia de la ciudad $^{14}$. Si bien la promulgación de la ley de Barrios Marginales № 13517 en 1961 marca un giro hacia el reconocimiento de las ocupaciones que dieron lugar a las barriadas e inicia un período de múltiples ensayos ${ }^{15}$ para responder a la demanda de vivienda de una población que continúa migrando, desde el Gobierno Central se sigue empujando un proyecto de modernización paralelo que obvia esa realidad. El rebrote de la migración debido a los desplazamientos forzados por a violencia política entre 1980 y el 1995 y la asunción en 1990 de un gobierno neo-liberal, populista y desde 1992 antidemocrático, que instituyó una agresiva política nacional de flexibilización de requisitos para el acceso a la formalización de diversos aspectos de la economía y la vida urbana, que se traduciría en una masiva entrega de títulos de propiedad a cargo de COFOPRI ${ }^{16}$, creada en 1996. Además, se flexibilizaron los marcos legales, se liberalizó el acceso al suelo en detrimento del Estado y de formas tradicionales de propiedad y tenencia de suelo. Estas medidas no han impedido que la informalidad aumente como lo confirman algunos datos claves, por ejemplo, los Barrios Urbano Marginales aumentaron de 2705 en el 2002 a 4453 en el 2007 (Calderón, 2019, p. 51). Esto se debió principalmente a que algunas de las medidas que el Estado para resolver el problema, bajo la forma de amnistías, subsidios y excepciones de distinto tipo, constituyen una motivación a seguir invadiendo ${ }^{17}$, el propio Estado boicotea sus acciones. La experiencia en Lima es similar en otros

14 Entre 1945 y 1949 se crearon la Corporación Nacional de la Vivienda (CNV), la Oficina Nacional de Planeamiento Urbano (ONPU) y se realizó el Plan Piloto de Lima, primer plan moderno, y la UV3, el primer conjunto de vivienda siguiendo las prescripciones de las Unidades Vecinal (Neighbourhood Unities).

15 Nos referimos a los proyectos de habilitación urbana con núcleos básicos, lotes con servicios y otras modalidades ensayadas en distintos lugares del Perú.

16 COFOPRI es la Organismo de Formalización de la Propiedad Informal, creada el año 1996 bajo la asesoría de Hernando de Soto y las ideas expresadas en El otro sendero, publicado ese mismo año.

17 En el siguiente párrafo, Julio Calderón lo hace explícito, sin embargo, son situaciones se dan en otros países de la región tanto como en India o Tailandia, son los gobiernos de turno, populista, que invalidan la propia política. "En forma paralela a la titulación, continuó la tradición del derecho urbano peruano de aplicar sucesivas amnistías a los invasores de tierras. Con el gobierno de Alberto Fujimori se tuvo la ley 26264 de 1993 y el decreto legislativo 803 de 1996. Posteriormente, con el gobierno de Alejandro Toledo, el decreto supremo 021 del Ministerio de Justicia de junio del 2002 y la ley 28391 de noviembre de 2004. Finalmente, con el gobierno de Ollanta Humala el decreto legislativo 1202 de septiembre de 2015. Estos dispositivos 
países y continentes, donde también se logran mejoras parciales, empeorando simultáneamente otros aspectos de la vida de la población (Roy, 2007, p. 49).

De otro lado, la promoción de la titulación individual en sectores de la ciudad con una larga tradición comunal ha debilitado esos lazos, construyendo una cultura clientelar que se renueva con el gobierno de turno, así, "La titulación promovió un mayor individualismo, una reducción del comunitarismo y una afectación de la organización social"18 (Ramírez \& Riofrío, 2006, en Calderón, 2019, p. 55). Esto podría plantear una dicotomía diferente a la oposición inicial Estado-informalidad, la de Estado-comunitarismo, esto quiere decir que de la misma manera como la informalidad se percibe como un obstáculo para alcanzar la modernidad, lo comunitario es presentado como un problema para alcanzar el desarrollo y la modernidad, a pesar que lo comunitario ha sido incorporado al sistema legal ${ }^{19}$. En este punto se plantea una contradicción fundamental, si las normas deben provenir de la sociedad, de la manera como esta se ha constituido y de los lazos construidos en su interior ¿cómo el estado podría sentirse limitado por el vínculo comunitario? Lo informal y lo comunitario se entienden como obstáculos desde el Estado, sin embargo, si escalamos este razonamiento y lo confrontamos a los porcentajes de informalidad existentes en el Perú, donde en promedio sólo el $30 \%$ de las actividades y la población estarían ajustados a la ley, se debe preguntar si el Estado no está estructurándose para servir solo a ese $30 \%$ del país, dejando fuera al resto de la población y actividades. En el tema de la informalidad suele apuntarse a las consecuencias y no siempre a las causas, se insiste en que debe aligerarse la carga burocrática y los trámites, sin embargo, la diferencia de oportunidades, causa estructural, y los posibles caminos para su solución se invisibilizan, por ejemplo, es obvio que "...la titulación sin una contraparte en programas de vivienda y suelo urbano genera el círculo vicioso de la informalidad" (Calderón, 2019, p. 56), pero el debate no se centra en la política de vivienda. ¿Cuál es el camino para salir del círculo vicioso de la informalidad? En los textos de la mayor parte de expertos en el tema se sugiere, implícitamente, la necesidad de ampliar la mirada, de no enfocar el problema en la mejora de las condiciones materiales de la sociedad, sino partir del origen, que el estado está obligado a garantizar que todos los miembros de su sociedad tengan las mismas

continuaron alimentando en los pobres la expectativa que la informalidad urbana consistía, realmente, el medio de atender al problema de la vivienda" (Calderón, 2019, p. 54).

18 Ramírez-Corzo y Riofrío se refieren, entre otros, a casos como el de la Comunidad Autogestionaria de Huaycán o al Proyecto de la Comunidad Urbanas de Villa el Salvador, ambas en Lima, ejemplos paradigmáticos, pero no los únicos, en los que existe un vínculo comunitario que sin embargo se disuelve al momento de regularizar y formalizar la propiedad individual, el lote.

19 SI bien, este debate que se reedita cada ve que reaparecen los conflictos entre las empresas con concesiones para explotar recursos naturales y la organización comunal que exige cumplir ciertas condiciones ambientales. 
oportunidades frente a la ley y al propio estado. Es desde esta perspectiva que debemos observar la desregulación del Estado que genera la informalidad y que encarna problemas mucho mayores a la propia informalidad.

\section{El origen formal de lo informal}

Si se amplía el espectro temporal se verá que aquello que se llama informalidad proviene de mucho más atrás de 1972 cuando el término se acuñó. Muchas de las nociones contemporáneas respecto a la ciudad informal vienen de las observaciones y escritos de John Turner ${ }^{20}$, cuyo sesgo ideológico anarquista dirigió la reivindicación de la autogestión comunitaria a niveles superlativos, sin pensar que serían en parte argumentos para el debilitamiento del Estado. Llegado al Perú en 1957, un momento clave para el estudio de las barriadas ${ }^{21}$, se vinculó rápidamente a los arquitectos, urbanistas y científicos sociales que estudiaban los barrios urbano marginales bajo la mirada de José Matos Mar, un sociólogo que buscaba mediar entre Oscar Lewis y Robert Redfield, observando meticulosamente los procesos y productos de los migrantes, especialmente las barriadas, sus dinámicas y su vivienda. Matos Mar resalta el esfuerzo de la población organizada para la construcción de sus asentamientos: "Los pobladores son continuamente notificados para concurrir a "faenas"; por ej.: construcción de una carretera, limpieza y arreglo de calles, construcción de reservorio locales, campos deportivos, etc. En algunas barriadas funcionan un sistema de cotización, organizado por acuerdo mutuo..." (Matos, 1977, p. 156). Para el autor el trabajo comunitario no es suficiente, no llega a cumplir ni "medianamente" lo necesario y es imprescindible acudir las distintas instancias del gobierno, el Estado es aún necesario y se le reclama acción. Este el punto de partida de John Turner ${ }^{22}$ quien va aún más allá, señalando el rol del Estado sólo como articular de fondos, su

20 Al decir mirada contemporánea me refiero a un juicio de valor más abierto y que ve algunos valores positivos como el de John Turner, antes de cuya presencia de John Turner, desde le urbanismo y la arquitectura se tenia una mirada defectiva, el término barriada se usaba ya en artículos de El Arquitecto Peruano dirigida por el arquitecto Fernando Belaunde, sin embargo, eran consideradas tumores a extirpar. Esta debería entenderse como la mirada moderna, inspirada directamente de los escritos de Le Corbusier (Rodríguez, 2017).

21 En 1955 la Comisión de Reforma Agraria del Perú solicitaría a José Matos Mar la elaboración del primer Censo General de Barriadas de Lima, Arequipa y Chimbote, el que sería culminado y publicado un informa parcial en 1957. El estudio completo sería publicado en 1966 con el nombre Las barriadas de Lima (1957). Asimismo, la misma Comisión pediría a Adolfo Córdova la elaboración del estudio sobre el problema de la vivienda en el Perú, el que sería publicado en el año 1958 bajo el nombre: La vivienda en el Perú. Estado actual yevaluación de las necesidades. El proceso de ambos estudios era de domino de arquitectos como Carlos Williams (socio de Córdova) y Eduardo Neira, quien fuera el anfitrión de John Turner en Perú por haber estudiado juntos en el UCL de Londres.

22 Gran parte de estos razonamientos se encontraban ya en el informe de Matos Mar y conocidos por los allegados a Turner. 
libro:Vivienda, Todo el poder para los usuarios (1977) tenía como objetivo, según él mismo, demostrar que "las estructuras rediale ${ }^{23}$ y las tecnologías descentralizadoras, esto es, los sistemas locales autogobernados, constituyen los únicos métodos y medios capaces de proporcionar bienes y servicios satisfactorios, además de ser los únicos que garantizan el equilibrio ecológico" (Turner, 1977, p. 32). Entre 1955 y 1975 se desarrolla en el Perú un intenso pensamiento alrededor de la autogestión que concluye, de un lado en el Proyecto Experimental de Vivienda (PREVI), que mediante un concurso internacional pone en el centro de la discusión arquitectónica la opción de la vivienda y la urbanización progresiva, autoconstruida y autogestionada, y del otro, el proyecto de Villa El Salvador (VES) conducido desde SINAMOS ${ }^{24}$ en 1974 por la dictadura del general Juan Velasco Alvarado. Finalmente, la autogestión, la autoconstrucción y el autogobierno fueron convirtiéndose paulatinamente en el Perú, en una política de estado, recogiendo y sistematizando la experiencia de las propias barriadas. Estas formas de autogobierno plantean implícitamente la inoperancia del Estado para resolver las necesidades de parte de la población y que ellos construyan un sistema paralelo, en otras palabras, plantean la desregulación del propio Estado.

\section{La informalidad antes de la informalidad}

En los dos primeros acápites se ha expuesto las contradicciones en las que se incurre respecto a los sistemas de autorregulación surgidos en la ciudad, en particular en el caso peruano, pero no exclusivamente. Contradicciones que se generan de un lado, en la voluntad del gobierno de imponer sistemas de regulación de origen moderno-occidental en oposición a las formas de auto-organización existentes en el territorio con anterioridad, y del otro, al haber incentivado formas de autogestión y autoconstrucción cuando estas parecían convenir a la incapacidad del estado para acometer sus obligaciones. La desregulación que comporta la informalidad encuentra gran parte de sus causas en los procesos de migración originados en el siglo XX, sin embargo, se ha señalado poco las contradicciones en que incurrieron los estados nación modernos al imponer un modelo ajeno, a un palimpsesto formado por el régimen colonial y los usos y costumbres previos al mismo. En lo que sigue se

23 Si bien no se explica el término, puede entenderse que se tratan de estructuras circulares sobre el mismo cuerpo.

24 SINAMOS, Sistema Nacional de Movilización Social, fue un organismo creado para ayudar a la población de las barriadas y a la población migrante a resolver sus problemas de hábitat, empleo y en general de bienestar. Se convirtió en una suerte de laboratorio con politólogos y científicos sociales de orientación marxista, de la talla de Hugo Neira, Carlos Franco, Héctor Béjar, entre otros. 
tratará de argumentar que la informalidad proviene de la desregulación del lugar del estado generada en el plano simbólico, debido a sus propias contradicciones.

\section{Desregulación y corrupción en la Colonia}

De todo lo explicado debe entenderse que la informalidad es, en el plano simbólico, esa desregulación del lugar de enunciación del discurso del Estado. Si bien en la teoría política todos los ciudadanos deben pertenecer al Estado, cuando en los hechos una parte de la ciudadanía no se siente parte de él, una escisión empieza a producirse, llevando al individuo y a la colectividad a buscar resolver sus problemas con sus propios recursos y esfuerzo, construyendo un "estado alterno", y sin esperar nada del Estado oficial ${ }^{25}$. En ese momento el lugar de enunciación se hace viscoso, ilegible e inentendible, sin que necesariamente desaparezca. Como lo menciona Hernando De Soto, el lugar es percibido como una zona de penumbra donde el Estado es visible, pero difícilmente distinguible. Se trataría de la misma dificultad que el Estado tiene para ver a cierta parte de la población como parte de él y atenderla como a los demás. Sin embargo, esta desregulación no es patrimonio de los estados imperiales o nacionales del siglo XIX y XX, en el intento de rastrear su origen se llega casi al inicio de los procesos de colonización, en la primera mitad del siglo XVI. En 1545 se descubre accidentalmente el que fue tal vez el yacimiento de plata más grande de la América española, el cerro de Potosí. Su importancia fue tan grande para el Virreinato que el sistema de ciudades y caminos que se consolida a partir de su explotación define en parte del manejo del territorio hasta entrado el siglo XX, y fue tal la cantidad de plata que un cargamento normal requería de dos mil llamas y mil indios para trasladar 7,771 barras de plata (Baptista, 2011, p. 24), de hecho, la plata de Potosí permitió masificar el uso de monedas en todo Europa. En 1568 se instala en Lima la Casa de la Moneda con la finalidad de disminuir el peso de los envíos de barras. Cuatro años después, en 1572, se estimó que se había perdido en plata un equivalente a 76 millones de pesos y que existían en el mercado 36 millones de pesos falsos, se trató de uno de los primeros escándalos de corrupción en el Virreinato. Esto obligó a tomar medidas, la primera, instalar un establecimiento de acuñación en el mismo lugar, para lo que se adapta el recién acabado Pabellón de Oficiales Reales, para el funcionamiento de la Casa de la Moneda de Potosí, la que empieza a funcionar ese mismo año. En 1618 nuevamente se observan signos de fraude

25 La idea que la población que migró construye un estado paralelo, otro Perú, está presente en "El Desborde Popular y Crisis del Estado" (1986) de José Matos Mar. 
en la cantidad de piezas de plata, que son referidos al Virrey, iniciándose una investigación interna. En 1623 se observa falta de ley en las monedas producidas, desprestigiándose la producción incluso en Cartagena (Caporosi, p. 66). Finalmente, en 1648 se inicia una investigación oficial que es encargada a Nestares Marín, quien luego de XX años emite su dictamen acusando a el ensayador Felipe Ramírez de Avellaneda, al abastecedor industrial Francisco Gómez de la Rocha -a cuyo apellido se debe el sobre nombre "rochanas" con el que se conocían las monedas falsas- condenado a morir al garrote, quien sin embargo era allegado del marqués de Mancera, Virrey del Perú en ese momento, que fuera cambiado luego del escándalo (Caporosi, p. 67). La corrupción registrada en este proceso proviene de las cabezas del propio régimen colonial, como si un régimen paralelo se hubiese instalado simultáneamente, como si el régimen colonial generase su propia desregulación.

Llegado el siglo XVIII la corrupción parece haber llegado a ser un problema estructural en las colonias hispanas, un informe de Antonio Ulloa y Jorge Juan de $1749^{26}$ se ocupa de evaluar actividades en Lima, Quito, Cartagena, Panamá y os puertos de Chile, observando irregularidades de diverso tipo en las rutas entre los puntos señalados, los más comunes eran el contrabando y el cohecho, señalándose además fraudes en el abastecimiento de suministros, el abuso a los indígenas con la complicidad de funcionarios, sacerdotes y hacendados, la colusión entre deudores al fisco y cobradores, entre otros. La corrupción era sostenida porque: "Para su beneficio privado, los virreyes imponían un gravamen obligatorio a quienes ya habían sido nombrados corregidores por el rey (...) de esta manera, los abusos cometidos por los funcionarios subalternos quedaban protegidos y se multiplicaban por doquier ${ }^{27 "}$ (Quiroz, 2013, p. 76). La corrupción provenía de la más alta autoridad, del propio representante del Rey que implicaba a los más altos funcionarios, y estas prácticas iban pasando de jerarquía en jerarquía hasta llegar a los propios curacas. Se encontraban afectas, incluso las cajas de censos de indios que les permitía sufragar los

26 El informe se titula "Discurso y reflexiones sobre el estado presente de la Marina de los reinos del Perú, su gobierno, arsenales, maestranza, viajes, armamentos, plana mayor de oficiales, sus sueldos, de los navíos, marchantes, gobierno, régimen particular de aquellos agitadores, y abusos que se han introducido en uno y otro. Dase individual noticia de las causales, de su origen, y se proponen algunos medios para evitarlas. Escritas por orden del Rey, Nro. Sor. Por Don Jorge Juan, Comendador de Águila ene I Orden de San Juan, y Don Antonio de Ulloa, miembros de la Real Sociedad de Londres, socios correspondientes de la Academia Real de las Ciencias de Paris, y Capitanes de Navío de la Real Armada. Año de 1749. Del uso del Sr. Dr. D. José Antonio de Areche de la distinguida RI. Orn. Española de Carlos III del Consejo de S.M. en el Supremo de Indias y Visitador General de los reinos del Perú" (Quiroz, 2013, p. 60).

27 La corrupción en la más alta autoridad llegaba al punto de conceder indultos, en el día de su cumpleaños, "a una tasa acostumbrada de hasta cuatro mil pesos" (Quiroz, 2013, p. 76). 
gastos imprevistos y de urgencia de las comunidades ${ }^{28}$, es decir que la población nativa no solamente sufría el abuso de los funcionarios españoles, sino que era víctima y testigo de como estos en complicidad con la iglesia y las propias autoridades indígenas, afectaban un fondo de carácter compensatorio otorgado por la propia Corona a la colectividad. No fue ni el primero ni el últimos de los informes ${ }^{29}$ y en algunos casos, como el del período 1710 a 1719, los actos de corrupción llegan a un $88 \%$ del gasto público.

Es la propia naturaleza de lo colonial, con su autoridad deslocalizada, invisible e inasible, la que origina un sistema de responsabilidades delegadas, compartidas y que se van perdiendo en las demoras para reaccionar, en las órdenes no cumplidas y las interpretaciones tergiversadas. Los abusos coloniales siempre fueron condenados en las normas mientras que en la realidad continuaban creciendo, las historias viajan a través de océanos y siglos. Hacia 1507 asume el trono del reino del Congo Nzinga Mbemba cuyo nombre cristiano sería Alonso I. Su profunda fe cristiana lo llevó al convencimiento que el desarrollo de su reino sólo sería posible si se asumía la fe que él profesaba y las costumbres occidentales que los portugueses habían llevado a sus tierras, por lo que se esmeró en firmar acuerdos de asistencia religiosa y tecnológica el rey Manuel de Portugal. En su entusiasmo por asumir la cultura europea ${ }^{30}$, introdujo transformaciones urbanas, agrícolas, gastronómicas, etc, para beneplácito de los portugueses. Simultáneamente, en la isla Santo Tomé descubierta por los portugueses en 1470 , se instala una colonia penal, sin embargo, pronto iba escala obligatoria en el camino a la India, por lo que comenzó a habitarse y pronto a plantarse café y caña de azúcar, comprando esclavos de la hoy Nigeria para las faenas del campo. Todo parecía ir por cauces adecuados hasta que los españoles iniciaron la colonización y construcción de su imperio en América, demandando mano de obra de bajo costo, momento en que los comerciantes de Santo Tomé se involucraron en el comercio de esclavos, obteniendo del Rey Manuel I una concesión que los traficantes excedieron largamente, comenzando el despoblamiento de los territorios de Alfonso. El Rey del Congo envía innumerables cartas

28 Se trataba de una "renta asignada a as comunidades indígenas (que) había sido asignada en parte para compensar la expropiación inicial de tierras comunales, así como para asegurar el pago del tributo y sufragar los gastos de rituales religiosos en tiempos difíciles, cuando los indios no podían efectuar gastos" (Quiroz, 2013, p. 69)

29 El mismo Alonso Quiroz señala otro de 1622 escrito por Juan de Aponte y uno posterior de Antonio Ulloa y además un ciclo marcado por el alza de la corrupción en los períodos de la segunda mitad del siglo XVII a inicios del XVIII, otro de 1750 a 1770 y finalmente uno de 1790 hasta 1821, la independencia /Quiroz, 2013, p. 121).

30 El mismo rey Alfonso se vestía como portugués y cada vez más asumía las costumbres, ademanes y apariencia de los europeos, vistiendo mantas capas y túnicas, dejando de lado rituales y costumbres propias del Manicongo (rey del Congo) (Forbath, 2002, p. 131). 
a su homólogo de Portugal pidiéndole un embajador que ponga orden entre sus súbditos, pero Manuel había decidido limitar la actividad de los traficantes para que sea la corona portuguesa se haga cargo del comercio de esclavos del continente, para lo que envía una expedición en 1512. Sin embargo, el control de la ruta a Congo que desde Santo Tomé tenían los traficantes impidió el intento de la Corona portuguesa, decidiéndose finalmente aliarse y traicionar a Alfonso I (Forbath, 2002, pp. 137-139). En su intento de detener el salvaje comercio humano Alfonso escribe al Papa, en el Vaticano se encontraba su hijo Enrique quien había sido ordenado obispo. El Vaticano nunca respondió, para 1526 ya los caciques locales, a espaldas de Alfonso, contribuían a la saca de esclavos. El rey del Congo viendo pérdidas las posibilidades de occidentalizar el Congo y de salvar a su población de la esclavitud, envía al sucesor de Manuel I una carta con 10 de sus descendientes para ser educados en Lisboa, el barco nunca llegaría a Europa, serían apresados en Santo Tomé, esclavizados y vendidos a Brasil (Forbath, 2002, pp. 141-143).

En 1901, casi tres siglos después de la política portuguesa del doble discurso con el reino del Congo, John Casement recorre los territorios del Ilamado Congo Belga en calidad de Cónsul de la corona inglesa con la finalidad de verificar las denuncias de abusos de parte de los colonos a la población, en el contexto de la explotación del caucho. El Informe general del Sr. Casemet al marqués de Lansdowne (Casement, 2010) es un relato de las observaciones, los diálogos sostenidos con autoridades y con la población, además de algunos interrogatorios al personal encargado del control de la recolección del caucho, la mayoría congoleses bajo las órdenes de las compañías contratadas por el imperio belga de la explotación. A lo largo del relato principal como de las notas informativas a manera de anexos, Casement da cuenta del procedimiento habitual para el control del caucho recolectado. A cada miembro de la cuadrilla se le asignan un número de canastas, el controlador debe llevar una cantidad de canastas de caucho; las canastas faltantes deben ser entregadas con un equivalente en canastas con manos humanas cortadas a los miembros de la cuadrilla que no cumplieran con su cuota. A esto se suman trabajos forzados, desplazamiento de población de su lugar de origen, rapto de mujeres, entre otras formas de abuso. Para 1901 la esclavitud había sido prohibida en todas las colonias europeas, sin embargo, las fotografías del informa Casement muestran nativos encadenados, mutilados (Casement, 2010, pp. 205-208). En su texto El crimen del Congo (2010) Arthur Conan Doyle hace un relato similar de las condiciones de esclavitud, tortura y muerte de los congoleses en manos de las empresas del caucho contratadas por Leopoldo II. 
La corrupción no es equivalente a la informalidad, sin embargo, la corrupción va sedimentando la autoridad, corroyendo el prestigio y la imagen del Estado, lo que provoca la desregulación del lugar del discurso del amo, sumiéndolo en esa profunda obscuridad que provoca otro sendero, esa suerte de estado paralelo que es lo informal. Los casos mostrados en tiempos coloniales nos permiten apreciar aspectos inherentes a los regímenes coloniales, el primero es que la administración colonial es una delegación de facultades de un poder que no se hace presente, lo que trae consecuencias para la subjetividad de los colonizados y los colonizadores. Los colonizados, quienes siempre tuvieron a sus mandatarios a la vista, se ven obligados a recibir órdenes de un lugar cuyo origen no es tangible, el lugar de enunciación de las reglas que definen la vida del colonizado se encuentra borroso, desregulado. En la mayor parte de veces la autoridad local se mantuvo presente durante la colonización - fue el caso del Inca, de Moctezuma, de los Emires, Rajás y reyes en África - con atribuciones restringidas y un poder casi inexistente. Los jerarcas nativos se mantuvieron siempre jerárquicamente por debajo de los administradores locales o virreyes y ambos siempre a la expectativa de lo que se decidiera en la metrópoli. Las autoridades presentes en el territorio no eran la última palabra, todo podía ser revocado con una orden del rey a quien se podía apelar todas las decisiones. Como se ha visto, son muchas las historias de reyes 0 nobles locales que escribían al rey para apelar decisiones o denunciar situaciones 0 conductas irregulares, la extensa carta de Huamán Poma puede ser considerada "el primer tratado contra la corrupción" del mundo colonial (Quiroz, 2012, p. 77). Desde el lado del colonizador las cosas no son menos graves, la ausencia del monarca da lugar a abusos y corrupción desde el inicio, sucedió en México y Perú en América, en el África del siglo XV y del siglo XIX, en Asia durante el siglo XIX; la metrópoli debe construir un sistema de vigilancia a sus propios administrados, en la América hispana los corregidores debían movilizarse por su jurisdicción permanentemente, existiendo además oidores que se encontraban en lo más alto de la jerarquía, sólo debajo del Virrey y, finalmente, los visitadores que acudían a las colonias cuando existían denuncias importantes. La lejanía abría la posibilidad a la corrupción y el abuso, la propia metrópoli debe espiar a sus funcionarios (Antonio Ulloa era uno de ellos) por lo que desde el propio estado se estructura un sistema de vigilancia informal. Una de las virtudes de la autoridad es ser justo, cuando la autoridad es injusta se deslegitima, es decir, su lugar de enunciación se desregula. Dado que toda colonización es una usurpación, toda colonización nace desregulada, está destinada a deslegitimarse, aún si su gobierno es adecuado. La masificación de la 
corrupción ensancha el límite entre lo legal y lo ilegal, en ese límite, siempre difuso, apareció lo informal en el mundo post-colonial.

\section{La informalidad como síntoma de los post-colonial}

La desregulación de lugar del discurso del amo genera la dificultad de un mutuo reconocimiento entre el estado y su población, los significados que emanan del estado se enrarecen de manera similar a como se enrarecen los significados desde las acciones y discursos de la comunidad. Como complemento, la imagen de la comunidad es ambigua para el estado, es una masa viscosa que no le es fácil identificar y comprender, que no pertenece a su registro, es otro, distinto a él mismo, de la misma manera como para el sector informal el estado es algo ajeno, es un Otro. La zona de penumbra es el área en que los discursos se desvirtúan producto de la desregulación que provoca que las intenciones nunca se materialicen, los resultados siempre están lejos de cumplir las expectativas, como escribe Julio Calderón, "Se produjo un desencuentro entre la intención del gobernante a la hora de expedir una ley y sus consecuencias" (Calderón, 2019, p. 57). Parte del desencuentro se produce cuando se mira al estado como un ente todopoderoso, responsable de lo que hace y deja de hacer a través de sus políticas públicas, programas y proyectos (Calderón, 2019, p. 46). Debe tomarse en cuenta que los estados-nación en el hemisferio sur nacieron empobrecidos, los regímenes coloniales succionaron toda la riqueza que pudieron, fracturaron la sociedad, establecieron clases de ciudadanos y generaron una élite a sus imagen y semejanza. Las nuevas repúblicas nacen con deudas, miseria y una sociedad fragmentada, pero especialmente con un estado corto, porque la administración colonial sólo se interesó en gestionar y administrar aquello que le rendiría frutos, difícilmente cubre todo el territorio, se ocupa de los enclaves y yacimientos importantes. En el proceso de reapropiarse el país, el estado sigue el ejemplo de las naciones europeas respecto al paradigma moderno, y en el trance de aplicar un modelo externo se empantana, arrastrando contradicciones a través del tiempo;"Tales conceptualizaciones rompen la fantasía mágica de Hernando De Soto en la que el Estado es simultáneamente el creador del "apartheid legal", excluyendo a los informales, y también el benevolente promotor de la legalización. En cambio, se hace evidente que la legalización de los sistemas de propiedad informales no es simplemente un problema burocrático o técnico, sino más bien una lucha política compleja." (Roy, 2007, p. 4). El estado acaba, por ejemplo, subsidiando la ciudad informal, generando las condiciones para su expansión permanente e incluso para el tráfico de tierras (Espinoza, 2020). Su capacidad para identificar causas y efectos, 
es limitada, no tiene claridad conceptual, en la informalidad del empleo ve como responsables a las empresas que no cumplen la ley, en la informalidad urbana son los sujetos que invaden los culpables y no siempre se evidencia la responsabilidad del estado (Calderón, 2019, p. 47) ${ }^{31}$. Los individuos son estigmatizados desde el estado, cuando ya eran marginales en derechos y posibilidades económicas son puestos al margen en términos simbólicos, devolviéndoles la responsabilidad de la informalidad y de la pobreza que esta trae a los propios pobres (Roy, 2007, p. 2).

Del estado se esperan decisiones justas, cuando ello no ocurre, cuando el estado gobierna y legisla para un sector cercano a el mismo, genera un estado de excepción, donde las normas no rigen para el soberano y los suyos, quienes quedan fuera del alcance de sus propias decisiones (Agamben, 1997, p. 29). Las contradicciones van minando la legitimidad del estado, oscureciendo el lugar desde el que su discurso se emite y desregulando sus propias acciones, por lo tanto, la informalidad es la última prueba de la inexistencia de un contrato social, y de la presencia de una escisión profunda entre el estado y una parte de la ciudadanía en la base misma de la definición del estado, que todos son parte de él. Eliminar la informalidad es probablemente imposible, en un mundo tan integrado siempre habrá migración, empleo informal y temporal, y gente viviendo informalmente, cierto nivel de informalidad es tal vez el costo de lo global, pretender eliminarla es como pretender eliminar ese resto imposible de ser eliminado. De otro lado, en la medida que el estado se entienda como un proyecto modernizador a imagen y semejanza del modelo europeo-occidental la brecha será mayor. Alrededor del mundo el sector informal está integrado por esa parte de los países más alejados física, étnica, cultural y productivamente, de los paradigmas y prejuicios que ese modelo ha producido. Mike Davis sea tal vez uno de los pocos que ha comprendido la dimensión simbólica de la informalidad, cierra Planeta de Ciudades Miseria (2007) con el caso de Kinshasa, una ciudad arruinada por la corrupción y el FMI, y con niveles de informalidad entre el 60\% y el 80\% (World Bank Group, 2018, p. 23) ${ }^{32}$. Más allá de las cifras, la capital del Congo es hoy un paisaje casi continuo de vendedores ambulantes con puestos mínimos frente a sus casas, sea en calles locales o en avenidas. Al no haber producción en el país, la mayor parte de ellos ofrecen

31 En la mayor parte de casos la informalidad urbana es precedida por el permiso o la decisión del estado de eliminar restricciones para la transformación de suelo agrícola en suelo urbano, normalmente bajo la presión de las élites que buscar obtener ganancias. Como dice Ananya Roy, la privatización y urbanización de las tierras de bordes son consecuencia de una política errada hacia el agro y el favorecimiento de las mercancías. (Roy, 2007, p. 3), este será el antecedente que abre las puertas al crecimiento informal e ilegal, el momento en que le estado mismo crea un estado de excepción.

32 Según las publicaciones del World Bank, 70\% del empleo es informal, $12 \%$ del sector privado formal y $17 \%$ del sector público. 
pan, minutos de teléfono celular, plátanos o golosinas. Es obvio estos pequeños negocios se encuentran al margen de las normas, sin embargo, responden a las condiciones económicas impuestas por el Estado y a la necesidad de subsistencia, la informalidad no es ilegalidad, aún cuando esté al margen de la ley.

Ya en el 2000 existían 2177 sectas religiosas en Kinshasa, muchas de las cuales recogen elementos propios de las creencias nativas (Davis, 2007, 258). Estas creencias suelen asociar las tragedias y el fracaso a maldiciones o embrujos, trayendo como consecuencia la expulsión de los hijos del hogar cuando muere un padre, llegando incluso a asesinarlos. Las calles de Kinshasa están llenas de esos niños y jóvenes víctimas de la brujería que pululan en las noches y que restructuran las relaciones familiares, maternales y en general con la autoridad (De Boeck, 2006, p. 98). Relaciones que, al desarrollarse en el espacio urbano, en el dominio de lo público, acaban invadiendo la esfera política, la que define los modos de vida de la sociedad, y desde ahí a la economía. "Les domaines de la famille, de l'échange, de l'argent, du marché, de la sexualité, de la puissance et de la violence sont sans arrêt retirés du symbolique pour se déplacer vers l'imaginaire. Et, à son tour, cet imaginaire devient quasiment ontologique et confère à la grande ville postcoloniale les qualités oniriques signalées plus tôt, par les quelles le citadin ne cesse d'essayer de combler les fossés creusés entre imaginaire et réalité" (De Boeck, 2006, p. 99). La ruptura que impone la modernidad a las creencias y tradiciones, atraviesa todos los aspectos de vida, trastocando el orden desde el que se imagina y reconstituyendo jerarquías y lugares, la informalidad es sólo el síntoma de esas rupturas y desregulaciones. Por eso para Mike Davis "el sector informal no es el "deux ex machina", sino "una tierra muerta y sin alma" al mismo tiempo que una "economía de resistencia", que proporciona a los pobres la posibilidad de desafiar la lógica del mercado que les conduce a la desaparición" (Davis, 2006, p. 262). Las aspiraciones del estado moderno ortodoxo plagado de contradicciones y situado él y las élites en un estado de excepción, no busca sino la desaparición de esa parte viscosa e incomprensible que es la población portadora de tradiciones y prácticas alternativas locales. Esa parte de la población y el estado son las dos partes escindidas de un mismo ser que se desconocen y se rechazan, sólo los procesos de reapropiación pueden volver a unir lo que los procesos de colonización escindieron, apropiarse de uno mismo, ser un poco como el otro. Las expresiones culturales y ciertas disciplinas ${ }^{33}$

33 Por ejemplo, en el derecho Sara Liwerant está explorando las posibilidades del derecho tradicional como alternativa para comprender la ética y moral en la sociedad congolesa. Violence urbaine et reaction policière à Kinshsa (RD Congo) Sens et nonsense. Puzzle de sorties de violence urbaine à Kinshasa. Sara Liwerant, Raoul Kienge-Kienge (2013) Publications du centre de criminologie de l'Université de Kinshasa. 
de las sociedades post-coloniales parecen haberlo comprendido, son expresiones híbridas, penetradas por lo moderno y lo tradicional, lo antiguo y lo contemporáneo, lo arcaico y utópico.

\section{Conclusiones}

La primera y más importante de las conclusiones es que el concepto de informalidad invisibiliza lo que podríamos entender como el problema de fondo, la constitución de un Estado-nación a imagen y semejanza de Europa, en territorios que al haber pasado por procesos de colonización, tener una base fragmentada, múltiples escisiones y la consecuente debilidad política y también de recursos, requerían otra forma de constituirse, una en la que el objetivo principal se dirija a encontrar acuerdos comunes a partir del reconocimiento de la diversidad, que se acompañe de procesos de reconciliación y se diseñe formas de representación equitativas, lo que no ocurrió en ningún caso. En este marco, la informalidad debe ser entendida como ese resto no simbolizado de ese estado-nación constituido sobre la base de un cimiento colonial de fisuras y por lo tanto inestable.

Una segunda conclusión es que, si bien existen rasgos comunes en distintas ciudades de lo que puede llamarse informalidad, la clave para desentrañar esa zona de penumbra que aparece indescifrable, está en buscar sus raíces en el proceso histórico previo a la fundación del estado-nación y como ciertos aspectos del período colonial referidos a un orden paralelo y no integrado a la administración general, han pasado al período republicano sin resolverse. Es en ese análisis de carácter histórico-político-económico-urbano que pueden encontrarse continuidades y discontinuidades que permitirán que la franja se aclare y se puedan tomar decisiones adecuadas. 


\section{Bibliografía}

Agamben, G. (1997). Homo Sacer. Le pouvoir souverain et la vie nue. Éditions du Seuil.

Baptista, M. (2011). La ciudad de Potosí vista por viajeros y autores nacionales del siglo XVI al $X X I$. Fondo editorial de la Casa de Moneda de Potosí.

Bayode, O. (2020). Shanty settlements in nineteenth-century Europe: Lessons from comparison with Africa en U. Grashoff (Ed.), Comparative approaches to informal housing around the globe (pp. 186-201). UCL Press.

Calderón, J. (2005). La ciudad ilegal. Lima en el siglo XX. UNMSM.

Calderón, J. (2019). El Estado y la informalidad urbana. Perú en el siglo XXI. Pluriversidad, 45(3), (pp. 45-64). DOI: https://doi.org/10.31381/pluriversidad.v3i3.2234

Caporossi, O (2007). La falsificación de moneda en la América Hispana a mediados del siglo XVII: entre reformación administrativa y represión judicial. Anuario Americanista Europeo. (pp. 4-5, 65-82).

Casement, R (2010). Informe general del Sr. Casment al marqués de Landsowne. En La tragedia del Congo. Ed. Alfaguara.

Cosamalón, J. (2018). El apocalipsis a la vuelta de la esquina. Lima, la crisis y sus supervi-vientes. Pontificia Universidad Católica del Perú, Fondo Editorial.

Dasuky, S. A. (2010). Discurso del Amo: de Hegel a Lacan. Escritos, 18(40), (pp. 100-124).

Davis, M. (2007). Planeta de ciudades miseria. Foca ediciones.

De Boeck, F. (2006). La ville de Kinshasa une architecture du verbe. Espirit, 12, (pp. 79-105). DOI: 10.3917/espri.0612.0079

De Soto, H. (1987). El otro sendero. Instituto Libertad y Democracia.

De Soto, H (2000). El misterio del capital. Ed. El Comercio.

Espinoza, A. y Fort, R. (2020). Mapeo y tipología de la expansión urbana en el Perú. Grupo de Análisis para el Desarrollo (GRADE).

Fanon, F. (1952). Peau noires, masques blancs. Éditions du seuil.

Forbath, P. (2002). El río Congo. Descubrimiento, exploración y explotación del río más dramático de la tierra. Fondo de Cultura Económica.

International Labour Office (1972). Employment, incomes and equality. A strategy for increasing productive employment in Kenya. Geneva.

Lacan, J. (2009). El estadio del espejo como formador de la función del yo [Je] tal como se nos revela en la experiencia psicoanalítica. En J. Lacan, Escritos 1, (pp. 99-105). https:// arditiesp.files.wordpress.com/2012/10/lacan_estadio_del_espejo.pdf

Lewis, O. (1965). Los hijos de Sánchez. Fondo de cultura económica.

Matos, J. (1977). Las barriadas de Lima 1957. IEP.

Myers, G. (2012). African Cities: Alternative Visions of Urban Theory and Practice [Kindle version]. https://Amazon.com

Quiroz, A. (2013). Historia de la corrupción en el Perú. IEP.

Ramírez, D y G. Riofrío (2006). Formalización de la propiedad y mejoramiento de barrios: Bien legal, bien marginal. DESCO.

Renault, M. (2018). Frantz Fanon et la décolonisation des savoirs. LAM- Les Afriques dans le monde. https://halshs.archives-ouvertes.fr/halshs-01925477 
Riofrío, G. (1986). Habilitación urbana con participación popular. Tres casos en Lima. GTZ Eschborn.

Robinson, J. (2006). Ordinary cities. Between modernity and development. Routledge.

Rodríguez, L (2017). Espacio en el tiempo y la construcción de la vanguardia moderna en el Perú. El discurso de Luis Miró Quesada. Prólogo a Espacio en el Tiempo. La arquitectura moderna como fenómeno cultural. PUCP.

Rodríguez, L (2020). Les imaginaires urbains et le futur de la ville. Appropriations et postcoIonialité. [Tesis doctoral, Universidad Versalles St. Quentin].

Roy, A. (2005). Urban Informality. Toward an Epistemology of Planning. Journal of the American Planning Association, 71(2), (pp. 147-158).

Roy, A. (2009). Strangely Familiar: Planning and the worlds of insurgence and informality. Planning Theory, 8(1), (pp. 7-11). DOI: 10.1177/1473095208099294

Roy, A. (2011). Slumdog Cities: Rethinking Subaltern Urbanism. International Journal of Urban and Regional Research.35(2), (pp. 223-238). DOI:10.1111/j.1468-2427.2011.01051.x

Royer, J. (1932). L'Urbanisme aux Colonies et dans les pays topicaux. Paris.

Sanyal, K. (2014). Rethinking Capitalist Development. Primitive Accumultion, Governmentality \& Post-Colonial Capitalism. Routledge Taylor \& Francis Group.

Turner, J. (1977). Vivienda, todo el poder para los usuarios. Hacia la economía en la construcción del entorno. Rosario: $\mathrm{H}$. Blume Ediciones.

World Bank (2018). Informe Anual 2018 del Banco Mundial. World Bank. http://documents1. worldbank.org/curated/en/630671538158537244/pdf/The-World-Bank-AnnualReport-2018.pdf 